\title{
Trends in Cystic Fibrosis survival over 40 years in South Africa: an observational cohort study
}

\author{
Marco Zampoli ${ }^{1}$, Reshma Kassanjee ${ }^{2}$, Janine Verstraete $^{1}$, Anthony Westwood ${ }^{1}$, Heather \\ Zar $^{3}$, and Brenda Morrow ${ }^{1}$ \\ ${ }^{1}$ University of Cape Town Department of Paediatrics and Child Health \\ ${ }^{2}$ University of Cape Town School of Public Health and Family Medicine \\ ${ }^{3}$ University of Cape Town
}

November 1, 2021

\begin{abstract}
Introduction: Temporal trends in CF survival from low-middle-income settings are poorly reported. We describe changes in $\mathrm{CF}$ survival after diagnosis over 40 years from a South African (SA) CF center. Methods: An observational cohort study of people diagnosed with CF from 1974 to 2019. Changes in age-specific mortality rates from the year 2000 (versus before 2000) were estimated using multivariable Poisson regression. Data were stratified by current age $<$ or [?] 10 years and models controlled for diagnosis age, sex, ethnicity, genotype, and P. aeruginosa (PA) infection. A second analysis explored association of mortality with weight and FEV1z-scores at age 5-8 years. Results: 288 people ( $52 \%$ male; $57 \%$ Caucasian; $44 \%$ p.Phe508del homozygous) were included (median diagnosis age 0.5 years: Q1,Q3: 0.2, 2.5); 58 (35\%) died and 30 (10\%) lost to follow-up. Among age $>10$ years, age-specific mortality from year 2000 was significantly lower (adjusted hazard ratio aHR: 0.14; 95\% CI: 0.06,0.29; $\mathrm{p}<0.001$ ), but not among age $<10$ years (aHR: 0.67; 95\% CI: 0.28,1.64; $\mathrm{p}=0.383$ ). In children $<10$ years, Caucasian ethnicity was associated with lower mortality (aHR 0.17; 95\% CI 0.05,0.63), and time since first PA infection with higher mortality (aHR 1.31; 95\% CI 1.01,1.68). Mortality was 7-fold higher if FEV1z was $<-2.0$ at age $5-8$ years (aHR 7.64; 95\% CI 2.58,22.59). Conclusion: Overall, CF survival has significantly improved in SA from year 2000 in people older than 10 years. However, increased risk of mortality persists in young non-Caucasian children, and with FEV1z $<-2.0$ at age 5-8 years.
\end{abstract}

\section{Hosted file}

Survival Cystic Fibrosis South Africa PPULM.docx available at https://authorea.com/users/ 404411/articles/543876-trends-in-cystic-fibrosis-survival-over-40-years-in-south-africaan-observational-cohort-study

\section{Hosted file}

Tables 12 and 3 PPulm final.docx available at https://authorea.com/users/404411/ articles/543876-trends-in-cystic-fibrosis-survival-over-40-years-in-south-africa-anobservational-cohort-study 
A. All registry participants, by year of diagnosis

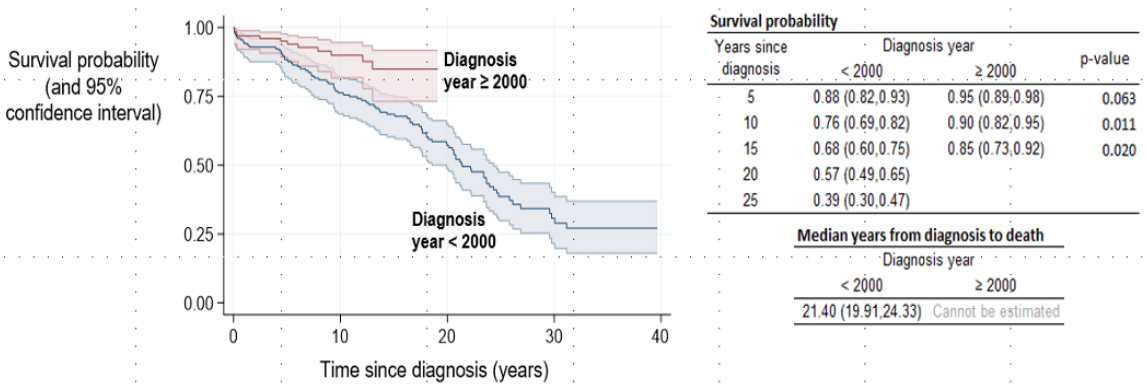

B. Participants with lung function measurement at age 5-8 years, by FEV1z

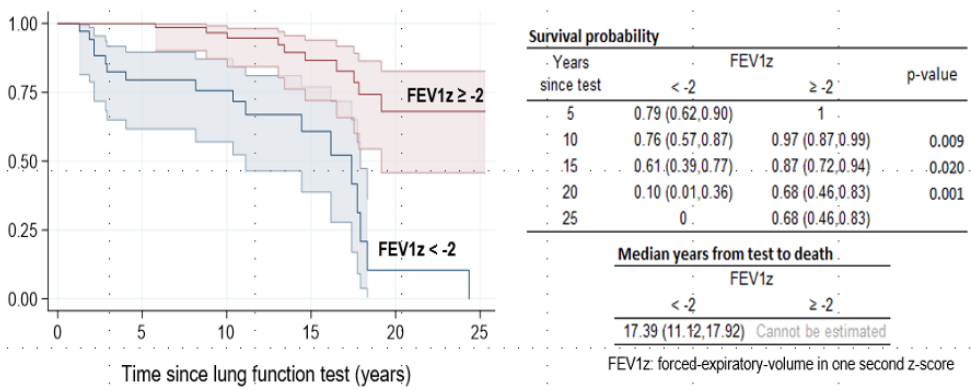

A. Age at death by time period

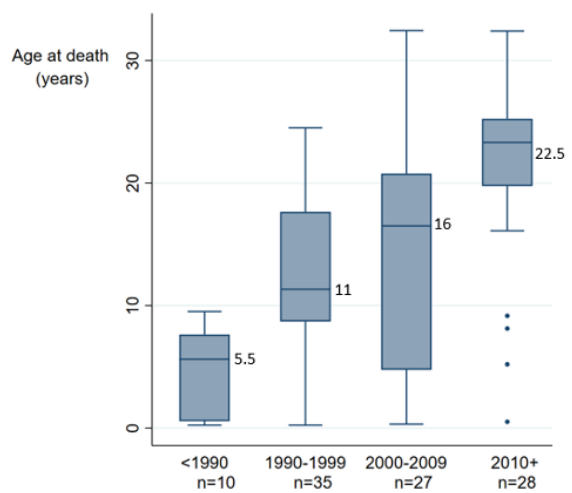

B. Age of participants in selected years

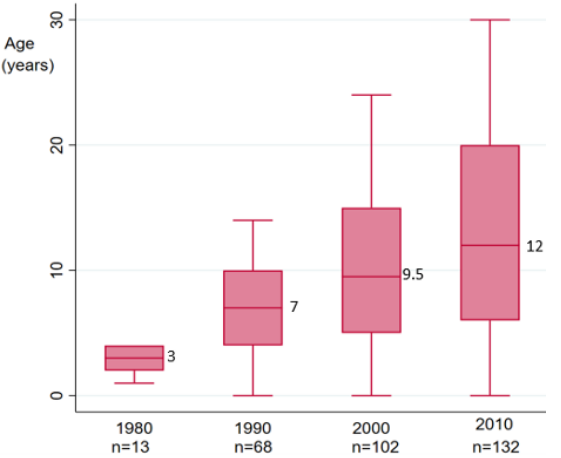




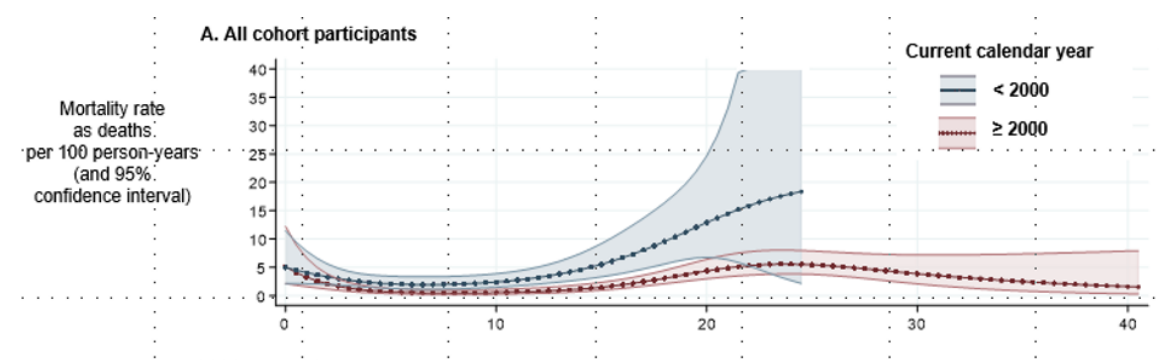

B. By ethnicity

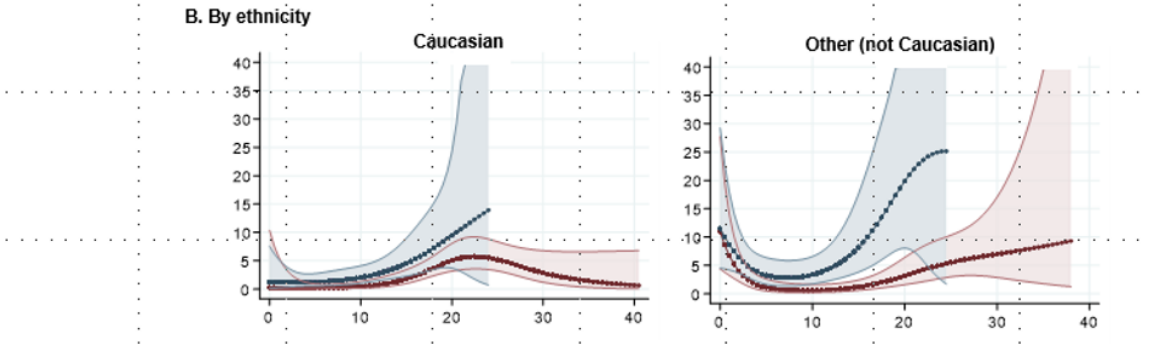

C. By lung function measurement at age 5-8 years

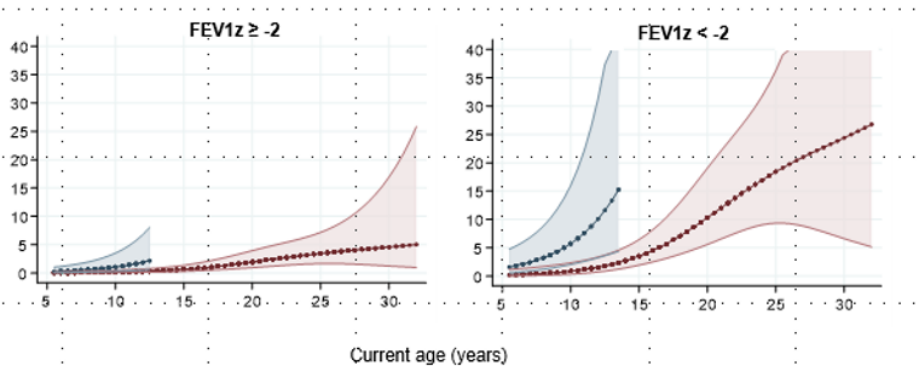

